\title{
Activating transcription factor 3 attenuates chemokine and cytokine expression in mouse skeletal muscle after exercise and facilitates molecular adaptation to endurance training
}

\author{
Rodrigo Fernández-Verdejo, ${ }^{*}$ Aline M. Vanwynsberghe, ${ }^{*}$ Ahmed Essaghir, ${ }^{\dagger}$ Jean-Baptiste Demoulin, $^{\dagger}$ \\ Tsonwin Hai, ${ }^{*}$ Louise Deldicque, ${ }^{*}$ and Marc Francaux ${ }^{*, 1}$ \\ ${ }^{*}$ Institute of Neuroscience and ${ }^{\dagger}$ De Duve Institute, Université Catholique de Louvain, Brussels, Belgium; and ${ }^{\ddagger}$ Department of Biological \\ Chemistry and Pharmacology, Ohio State University, Columbus, Ohio, USA
}

\begin{abstract}
Activating transcription factor (ATF)3 regulates the expression of inflammation-related genes in several tissues under pathological contexts. In skeletal muscle, at 3 expression increases after exercise, but its target genes remain unknown. We aimed to identify those genes and to determine the influence of ATF3 on muscle adaptation to training. Skeletal muscles of ATF3-knockout (ATF3-KO) and control mice were analyzed at rest, after exercise, and after training. In resting muscles, there was no difference between genotypes in enzymatic activities or fiber type. After exercise, a microarray analysis in quadriceps revealed ATF3 affects genes modulating chemotaxis and chemokine/cytokine activity. Quantitative PCR showed that the mRNA levels of chemokine C-C motif ligand ( $c c l) 8$ and chemokine C-X-C motif ligand ( $c x c l) 13$ were higher in quadriceps of ATF3-KO mice than in control mice. The same was observed for $c c l 9$ and $c x c l 13$ in soleus. Also in soleus, $c c l 2$, interleukin (il)6, il1ß, and cluster of differentiation $(c d) 68 \mathrm{mRNA}$ levels increased after exercise only in ATF3-KO mice. Endurance training increased the basal mRNA level of hexokinase-2, hormone sensitive lipase, glutathione peroxidase-1, and myosin heavy chain IIa in quadriceps of control mice but not in ATF3-KO mice. In summary, ATF3 attenuates the expression of inflammationrelated genes after exercise and thus facilitates molecular adaptation to training.-Fernández-Verdejo, R., Vanwynsberghe, A. M., Essaghir, A., Demoulin, J.-B., Hai, T., Deldicque, L., Francaux, M. Activating transcription factor 3 attenuates chemokine and cytokine expression in mouse skeletal muscle after exercise and facilitates molecular adaptation to endurance training. FASEB J. 31, 840-851 (2017). www.fasebj.org
\end{abstract}

KEY WORDS: inflammation $\cdot$ microarray $\cdot$ phenotype

Physical exercise is a valuable physiological stressor to maintain a healthy life. After each exercise bout, the expression of several genes transiently increases. These acute responses accumulate in the long term, producing measurable health benefits (1). Regular exercise enhances

ABBREVIATIONS: ATF, activating transcription factor; BiP, binding immunoglobulin protein; Cat, catalase; $c c l$, chemokine CC motif ligand; $c d 68$, cluster of differentiation-68; Con, control; COX IV, cytochrome c oxidase subunit IV; CS, citrate synthase; CSA, cross-sectional area; $c x c l$, chemokine C-X-C motif ligand; Epi, epididymal adipose tissue; ER, endoplasmic reticulum; GAPDH, glyceraldehyde-3-phosphate dehydrogenase; Gas, gastrocnemius; GLUT4, glucose transporter 4; gpx1, glutathione peroxidase-1; $h k 2$, hexokinase-2; $h s l$, hormone-sensitive lipase; $i l$, interleukin; $\mathrm{KO}$, knockout; myhc, myosin heavy chain; PFK, phosphofructokinase; Qua, quadriceps; SDH-A, succinate dehydrogenase subunit A; Sol, soleus; $\operatorname{tn} f \alpha$, tumor necrosis factor $\alpha ; V_{\max }$, maximal velocity

${ }^{1}$ Correspondence: Place Pierre de Coubertin 1, bte L8.10.01. 1348 Louvain-la-Neuve, Belgium. E-mail: marc.francaux@uclouvain.be

doi: $10.1096 /$ fj.201600987R

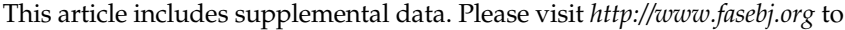
obtain this information. insulin sensitivity, improves lipid profile, and lowers blood pressure, among other benefits (2). Exercise also produces anti-inflammatory effects that reduce the risk of developing chronic metabolic diseases (3). Transcription factors play a key role in all these processes by regulating gene transcription.

Activating transcription factor (ATF) 3 belongs to the ATF/CREB family of transcription factors (4). In quiescent cells, atf3 expression is very low. However, its expression increases upon diverse stress signals (5). Hypoxia and endoplasmic reticulum (ER) stress, among others, upregulate atf 3 in various cell types (5). The response is rapid and transient, classifying atf 3 as an immediate-early gene (5). This type of gene coordinates the cellular response to different challenges. Accordingly, previous evidence suggests ATF3 works as a hub of the cellular adaptiveresponse network to restore homeostasis (5).

Depending on the cell/tissue and the stimulus, ATF3 up- or down-regulates the expression of different genes (5). For instance, ATF3 up-regulates T-cell lymphoma 
invasion and metastasis-2 during neutrophil development, a gene required for neutrophil chemotaxis (6). In Streptococcus pneumoniae-infected macrophages, ATF3 up-regulates interleukin (il) $1 \beta$ and tumor necrosis fac-

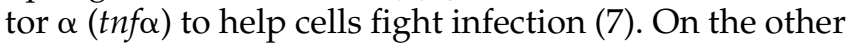
hand, in tumor-associated macrophages, ATF3 downregulates il12 and inducible nitric oxide synthase but up-regulates arginase-1 (8). ATF3 thus skews these macrophages to M2 bioactivity, a tissue-repair program hijacked by cancer cells to facilitate metastasis. Upon pulmonary inflammation, ATF3 down-regulates members of the chemokine CC motif ligand ( $c c l)$ and chemokine $\mathrm{C}-\mathrm{X}-\mathrm{C}$ motif ligand $(\mathrm{cxcl})$ families to attenuate inflammation (9). Together, the published data suggest that ATF3 regulates the immune response to stressful stimuli as an attempt to restore homeostasis.

As a physiological stressor, exercise induces atf3 expression in the skeletal muscle of mice, rats, and humans (10-14), as do other models of muscular activity, such as hind limb unloading/reloading, electrical stimulation of the sciatic nerve, functional overload, and eccentric contractions (15-19). Intriguingly, atf3 upregulation is usually one the highest among all the genes examined.

The normal response of skeletal muscle to exercise is essential to produce training-induced health benefits (3). The understanding of how those benefits initiate is of utmost importance. ATF3 is an attractive target, given its sensitivity to exercise and its role in homeostatic recovery in other tissues. The genes regulated by ATF3 in skeletal muscle and the relevance of this regulation are unknown. Hence, we aimed to identify genes regulated by exerciseinduced ATF3 in skeletal muscle and to analyze the consequence of the lack of ATF3 on molecular adaptations of skeletal muscle to training.

\section{MATERIALS AND METHODS}

\section{Animals}

C57BL/6JRj mice were from Janvier (Le Genest-Saint-Isle, France). The ATF3-knockout (ATF3-KO) mice have been previously described (20). ATF3-KO mice and their control (Con) littermates were used in the experiments. Mice were housed in a regulated environment (14:10 h light/dark cycle, $\left.22-24^{\circ} \mathrm{C}\right)$ and fed ad libitum with standard chow and water. Intraperitoneal injections of ketamine/xylazine were applied before isolation of tissues. The Committee for Ethical Practices in Animal Experiments of the Université Catholique de Louvain approved the procedures.

\section{Experiments}

Four independent experiments were designed to achieve different purposes.

\section{Atf3 expression kinetics and localization after exercise}

Male C57BL/6JRj mice (12-15 wk old) were familiarized to a treadmill (Exer 3/6; Columbus Instruments, Columbus, $\mathrm{OH}$, USA) by running $20 \mathrm{~min}(6-8 \mathrm{~m} / \mathrm{min})$ on 3 consecutive days.
Maximal velocity $\left(V_{\max }\right)$ was determined as follows: after $5 \mathrm{~min}$ at $5 \mathrm{~m} / \mathrm{min}$, the speed was set at $10 \mathrm{~m} / \mathrm{min}$ and then increased $2 \mathrm{~m} / \mathrm{min}$ every $3 \mathrm{~min}$ until exhaustion. Three days later, mice ran for $1 \mathrm{~h}$ at $50 \% V_{\max }$. Mice were killed at $0,1,3,5,8$, or $24 \mathrm{~h}$ after exercise. Resting mice were also killed. Quadriceps (Qua), soleus (Sol), and gastrocnemius (Gas) muscles, along with epididymal adipose tissue (Epi), were dissected.

Female C57BL/6JRj mice (31 wk old) ran $5 \mathrm{~min}$ on an inclined treadmill $\left(-6^{\circ}\right)$ at $7 \mathrm{~m} / \mathrm{min}$. The speed was then set at $10 \mathrm{~m} / \mathrm{min}$ and increased by $1 \mathrm{~m} / \mathrm{min}$ every $10 \mathrm{~min}$ until exhaustion. Mice were killed 1 or $3 \mathrm{~h}$ after exercise. Resting mice were also killed. Qua, Sol, and Gas muscles were dissected. One Qua was embedded in optimum cutting temperature (OCT) compound (VWR, Leuven, Belgium) and frozen in cold isopentane.

\section{Phenotype determination of ATF3-KO mice}

Male ATF3-KO and Con mice (13-15 wk old) were killed at rest. Qua, Sol, Gas, and tibialis anterior muscles were dissected. Epi, subcutaneous flank, and interscapular brown adipose tissue pads were also dissected. The lateral portion of 1 Qua per mouse was embedded in OCT compound and frozen in cold isopentane.

\section{Identification of ATF3-regulated genes}

Male ATF3-KO and Con mice (15-16 wk old) exercised the same as the female mice in experiment 1 but without treadmill inclination. Mice were killed $3 \mathrm{~h}$ after exercise. Resting mice were also killed. Qua and Sol were dissected.

\section{Effect of the absence of ATF3 on the response to endurance training}

Male ATF3-KO and Con mice (14 wk old) ran on a treadmill $60 \mathrm{~min} / \mathrm{d}, 5 \mathrm{~d} / \mathrm{wk}$, for $8 \mathrm{wk}$. The speed was $15.6 \mathrm{~m} / \mathrm{min}$, which represents approximately $65 \%$ of their $V_{\max }$ according to our previous observations. Two days after the last exercise session, $V_{\max }$ was determined in the trained mice. Another group of mice of each genotype remained sedentary throughout the study period. Qua, Sol, and Epi were dissected $48 \mathrm{~h}$ after the $V_{\text {max }}$ test.

\section{Tissue preparation}

After dissection, tissues were frozen in liquid nitrogen, powdered using a mortar and pestle, and stored at $-80^{\circ} \mathrm{C}$. The homogenous powder was used for the assays.

\section{RNA extraction, reverse transcription, and quantitative PCR}

Total RNA was extracted with Trizol (Invitrogen, Vilvoorde, Belgium). The RNA quantity and quality were assessed with a NanoDrop ND-1000 (Thermo Fisher Scientific, Wilmington, DE, USA). Reverse transcription was performed using the iScript cDNA Synthesis Kit (Bio-Rad, Hercules, CA, USA). Real-time PCR was done in the Bio-Rad MyiQ single-color detection system using IQ SYBR Green Supermix (Bio-Rad) and specific primers (Table 1). The quantitative PCR protocol was: 3 min at $95^{\circ} \mathrm{C}, 40$ cycles of $\left(30 \mathrm{~s}\right.$ at $95^{\circ} \mathrm{C}, 30 \mathrm{~s}$ at $58.4^{\circ} \mathrm{C}$, and $30 \mathrm{~s}$ at $72^{\circ} \mathrm{C}$ ), and $1 \mathrm{~min}$ at $95^{\circ} \mathrm{C}$. The geometric mean of 3 internal Cons was used for normalization as previously described (21). The internal Cons were: ribosomal protein L19 (rpl19), peptidylprolyl isomerase A (ppia), and hypoxanthine guanine phosphoribosyl transferase (hprt). 


\begin{tabular}{|c|c|c|c|}
\hline \multirow[b]{2}{*}{ Gene } & \multicolumn{2}{|c|}{ Primer, $5^{\prime}-3^{\prime}$} & \multirow[b]{2}{*}{ Accession no. } \\
\hline & Forward & Reverse & \\
\hline atf3 & CGAGCGAAGACTGGAGCAAA & ACAAAGGGTGTCAGGTTAGCA & NM_007498 \\
\hline cat & CCCCAACTATTACCCCAACAGCTTC & TGTGTAGAATGTCCGCACCTGAGT & NM_009804 \\
\hline ccl2 & CTTCTGGGCCTGCTGTTCA & CCAGCCTACTCATTGGGATCA & NM_011333 \\
\hline ccl8 & GCTTCTTTGCCTGCTGCTCATAG & AGGTGACTGGAGCCTTATCTGG & NM_021443 \\
\hline ccl9 & CCAGATCACACATGCAACAGAGACA & AATCCGTGAGTTATAGGACAGGCAG & NM_011338 \\
\hline$c d 68$ & ACCGCTTATAGCCCAAGGAAC & CGTGAAGGATGGCAGGAGAGTAA & NM_001291058 \\
\hline chop & CCTGAGGAGAGAGTGTTCCAG & CTCCTGCAGATCCTCATACCA & NM_007837 \\
\hline$c p t 1 b$ & GCGACAGGCATTTTCTTCTTCC & ACGGACACAGATAGCCCAGA & NM_009948 \\
\hline cxcl1 & ACCCAAACCGAAGTCATAGCCAC & ACAGGTGCCATCAGAGCAGTCT & NM_008176 \\
\hline $\operatorname{cxcl13}$ & GAACTCCACCTCCAGGCAGAATG & TAATGGGCTTCCAGAATACCGTG & NM_018866 \\
\hline $\operatorname{gadd} 34$ & CCTCTAAAAGCTCGGAAGGTACA & ATCTCGTGCAAACTGCTCCC & NM_008654 \\
\hline glut1 & GTGTATCCTGTTGCCCTTC & GCTTCTTCAGCACACTCTT & NM_011400 \\
\hline glut4 & TCGGCTCTGACGATGGGGAA & CACCTTCTGTGGGGCATTGATAACC & NM_009204 \\
\hline$g p \times 1$ & TCGGACACCAGGAGAATGGCAAGA & AGGAAGGTAAAGAGCGGGTGAGC & NM_008160 \\
\hline$h k 2$ & GCTAGGAGCTACCACACACCCT & ACTCGCCATGTTCTGTCCCATCC & NM_013820 \\
\hline$h p r t$ & AGGCCAGACTTTGTTGGATTT & CAGGACTCCTCGTATTTGCAG & NM_013556 \\
\hline hsl & TACGGGAAGGACAGGACAGCAA & AGGGCTCGTGGGATTTAGAGGT & NM_010719 \\
\hline$i l 1 \beta$ & ATGCCACCTTTTGACAGTGATG & GCTCTTGTTGATGTGCTGCT & NM_008361 \\
\hline il6 & TCGTGGAAATGAGAAAAGAGTTGTG & ATCCAGTTTGGTAGCATCCATCA & NM_031168 \\
\hline$l p l$ & GCCCTACAAAGTGTTCCATTACCA & GCAGTTCTCCGATGTCCACCT & NM_008509 \\
\hline myhc-I & GCTGTTTCCTTACTTGCTACCCT & TGGATTCTCAAACGTGTCTAGTGA & NM_080728 \\
\hline myhc-IIa & AGAGTCCCGAACGAGGCTGA & ACTCACAGACCCTTACTGGCAA & NM_001039545 \\
\hline$m y h c-I I x$ & ACGGTCGAAGTTGCATCCCTA & CCATCTCGGCGTCGGAAC & NM_030679 \\
\hline myhc-IIb & GTGAAGTGAAGACCAAGGAGGAGGA & TCGGGAAAACTCGCCTGACTCT & NM_010855 \\
\hline$p d k 4$ & TACTCCACTGCTCCAACACCTG & AGCCATAACCAAAACCAGCCAAAG & NM_013743 \\
\hline ppia & CGTCTCCTTCGAGCTGTTTG & CCACCCTGGCACATGAATC & NM_008907 \\
\hline rpl19 & GAAGGTCAAAGGGAATGTGTTCA & CCTTGTCTGCCTTCAGCTTGT & NM_009078 \\
\hline $\operatorname{sod} 2$ & GTTACAACTCAGGTCGCTCTTCAGC & CCTCCAGCAACTCTCCTTTGGGTT & NM_013671 \\
\hline$x b p 1_{\text {spliced }}$ & TGAGAACCAGGAGTTAAGAACACGC & CCTGCACCTGCTGCGGAC & NM_001271730 \\
\hline$x b p 1_{\text {total }}$ & GAAGAAGAGAACCACAAACTCCAGC & ATCCAGCGTGTCCATTCCCA & NM_013842 \\
\hline
\end{tabular}

\section{Protein extraction and dosage}

For Western blotting, previously described protocols were used to extract total (22) or fractionated (cytoplasmic/nuclear) (23) proteins. The fractionation was verified by analyzing the localization of histone 3 (nuclear) and glucose transporter 4 (GLUT4) (cytoplasmic) (not shown). Glyceraldehyde-3-phosphate dehydrogenase (GAPDH) was present in both fractions, although the cytoplasmic level was higher, as expected (not shown). Because GAPDH levels were unaffected by exercise, we used GAPDH as loading control for both fractions.

For enzymatic activities, muscle was mixed with lysis buffer (5 mM Hepes, $1 \mathrm{mM}$ EGTA, $0.1 \%$ Triton X-100, and $1 \mathrm{mM}$ DTT). After $1 \mathrm{~h}$ at $4^{\circ} \mathrm{C}$, samples were centrifuged $\left(10 \mathrm{~min}, 15,000 \mathrm{~g}, 4^{\circ} \mathrm{C}\right)$, and the supernatant was recovered.

Protein concentrations were determined using the DC Protein Assay package (5000116; Bio-Rad).

\section{Western blotting}

Proteins were separated by SDS-PAGE and then transferred to PVDF membranes. Membranes were blocked with $5 \%$ fat-free milk prepared in Tris-buffered saline with $0.1 \%$ Tween 20 for $1 \mathrm{~h}$ at room temperature. Membranes were incubated overnight $\left(4^{\circ} \mathrm{C}\right)$ with one of the following antibodies from Cell Signaling (Leiden, The Netherlands): ATF4 (11815), binding immunoglobulin protein (BiP) (3177), catalase (14097), eukaryotic elongation factor 2 (2332), p38 MAPK (8690), Phospho-p38 MAPK (Thr ${ }^{180} / \mathrm{Tyr}^{182}$ ) (9211), or superoxide dismutase-2 (13194); with one of the following antibodies from Sigma-Aldrich (St. Louis, MO, USA): $\alpha$-Tubulin (TG199) or ATF3 (HPA001562); with one of the following antibodies from Abcam (Cambridge, United Kingdom): cytochrome c oxidase subunit IV (COX IV) (ab14744) or GAPDH (ab9482); or with GLUT4 (MA5-17176; Thermo Fisher Scientific) or succinate dehydrogenase subunit A (SDH-A) (sc-59687; Santa Cruz Biotechnologies, Heidelberg, Germany). After washing with Tris-buffered saline with $0.1 \%$ Tween 20 , membranes were incubated $(1 \mathrm{~h}$, room temperature) with a horseradish peroxidase-conjugated antibody against rabbit (A6154; Sigma-Aldrich) or mouse (610-1319; Rockland Immunochemicals, Limerick, PA, USA). Chemiluminescent detection was done with WesternBright Quantum (Advansta, Menlo Park, CA, USA), and pictures were taken with a GBox (Syngene, Cambridge, United Kingdom). ImageJ $1.48 \mathrm{v}$ software (National Institutes of Health, Bethesda, MD, USA) was used for quantifications.

\section{Immunofluorescence}

Cryosections (5 $\mu \mathrm{m}$ thick) were cut in a cryostat (CM1850; Leica, Wetzlar, Germany) and fixated by incubation in methanol (5 $\mathrm{min}$, room temperature) and acetone $\left(-20^{\circ} \mathrm{C}\right.$, $1 \mathrm{~min})$. The samples were incubated with an ATF3 antibody (HPA001562; Sigma-Aldrich) for $1 \mathrm{~h}$ (room temperature, humid environment). After washing with PBS, samples were incubated (30 $\mathrm{min}$, room temperature, humid environment) with an anti-rabbit antibody (A11011; Thermo Fisher Scientific). After washing again, ProLong Gold reagent was applied (P36935; Thermo Fisher Scientific). Slices were visualized in a microscope (Eclipse E1000; Nikon, Amsterdam, The Netherlands), 
and the images were captured with NIS-Elements imaging (Nikon).

\section{Fiber typing and cross-sectional area}

Cryosections (7 $\mu \mathrm{m}$ thick) were cut with a cryostat (CM1850; Leica, Wetzlar, Germany). Fiber staining was done as previously described (24). Visualization of the slices and capture of the images were performed as described for immunofluorescence. We analyzed $557.8 \pm 119.9$ (mean \pm SD) fibers per mouse.

Fiber type-specific cross-sectional area (CSA) was determined with ImageJ $1.48 \mathrm{v}$. A minimum of 50 fibers from each type was used, as previously recommended (25). Only fibers IIax and IIb reached that minimum; therefore, only those fibers were analyzed.

\section{Enzymatic activities}

For citrate synthase (CS), proteins were mixed with Triton X-100 and reaction buffer [100 mM Tris base, 2 mM EDTA, $1.25 \mathrm{mM}$ malate, $0.25 \mathrm{mM}$ NAD and $6 \mathrm{U} / \mathrm{ml}$ L-malate dehydrogenase (10127256001; Roche, Mannheim, Germany)]. After the addition of acetyl-CoA, NADH production was measured by fluorescence.

For phosphofructokinase (PFK), proteins were mixed with reaction buffer $\left[57 \mathrm{mM}\right.$ Tris base, $7.4 \mathrm{mM} \mathrm{MgCl}_{2}, 74 \mathrm{mM} \mathrm{KCl}$, $0.38 \mathrm{mM}$ KCN, $2.51 \mathrm{mM}$ ATP, $1.51 \mathrm{mM}$ DTT, $0.29 \mathrm{mM}$ NADH, $0.37 \mathrm{U} / \mathrm{ml}$ aldolase (A8811; Sigma-Aldrich), $7.5 \mathrm{U} / \mathrm{ml}$ triosephosphate isomerase (T2391; Sigma-Aldrich), and 2.55 U/ml glycerol-3-phosphate dehydrogenase (10127752001; Roche)]. After the addition of fructose-6-phosphate, NADH consumption was measured by absorbance.

\section{Microarray}

The RNA quality was checked on Bioanalyzer nano 6000 chips (Agilent Technologies, Santa Clara, CA, USA). We selected only samples with a $260 / 280 \mathrm{~nm}$ absorbance of $1.9-2.0$ and with an RNA integrity number $>8.3$. The RNA of 4 mice per condition (Con at rest, Con after exercise, $\mathrm{KO}$ at rest, and KO after exercise) was pooled. MoGene 2.0 ST microarray chips (Affymetrix, Santa Clara, CA, USA) were used. The WT expression kit (Affymetrix) was used for single-stranded cDNA preparation. Hybridization, fluidics, and scanning were performed according to Affymetrix procedures. After the scan, quality assurance and gene-level Robust Multi-array Average normalization were done with the Affymetrix Gene Expression Console (Affymetrix). Using the Affymetrix Power Tools, we computed the signal detection above the background $P$ values. Only probe sets with a value of $P<0.01$ were considered. The Database for Annotation, Visualization, and Integrated Discovery (DAVID) (26) was used for functional annotation and pathway analysis, comparing genotypes at rest (KO.Revs. Con.Re), after exercise (KO. Exvs. Con.Ex), and in their response to exercise (KO.Ex/KO.Re vs. Con.Ex/Con.Re). A significant enrichment was considered if the modified Fisher exact value was $P<0.05$, which is equivalent to $-\log _{10}(P)>1.3$.

\section{Statistics}

Data are presented as means $\pm \mathrm{SD}$. Analyses were performed with Prism 7.0a (GraphPad Software, La Jolla, CA, USA). Outliers were identified using the Tukey test adjusted by sample size as previously described (27). One-way ANOVA was used in Fig. $1 A, E-G$ and in Supplemental Fig. $1 A, C$. Bonferroni post hoc corrected for multiple comparisons was used when appropriate. Two-way ANOVA with repeated measures was used in Fig. 2A. Unpaired Student's $t$ test was used in Figs. $2 B-K, 3 A, B$, and Supplemental Figure 2B. In Fig. $4 A, 2$-way ANOVA with repeated measures was used. All other analyses were done with 2-way ANOVA, with Bonferroni post hoc corrected for multiple comparisons in case of significant interactions. Bonferroni adjustment (28) was used to correct for multiple testing in Fig. 3F, G, J, K. A value of $P<0.05$ was considered statistically significant.

\section{RESULTS}

\section{Atf3 expression transiently increases in skeletal muscle after exercise}

In mice exercised $1 \mathrm{~h}$ at $50 \% V_{\text {max }}$, atf3 mRNA transiently increased in skeletal muscle (Fig. $1 A)$. The peak was observed $1 \mathrm{~h}$ after exercise (Qua, $53.3 \pm 15.3$-fold; Sol, $4.8 \pm 2.3$-fold; Gas, $1.9 \pm 0.2$-fold). ATF3 protein was undetectable in resting Qua but became detectable between 1 and $8 \mathrm{~h}$ after exercise (Fig. $1 B$ ).

Female mice were used only to determine ATF3 localization in Qua. These female mice showed a similar postexercise atf3 induction as their male counterparts (Supplemental Fig. 1A,B). Western blotting and immunofluorescence demonstrated that ATF3 localized mainly in the Qua nuclei after exercise (Fig. $1 C, D$ ). These female mice ran downhill $\left(-6^{\circ}\right)$, which promotes eccentric contractions that might damage muscle tissue, inducing macrophage infiltration $24-48 \mathrm{~h}$ after exercise (29). However, at the early timepoints we analyzed, no change in the macrophage-specific marker cluster of differentiation-68 (cd68) mRNA was found (Supplemental Fig. 1C).

In Qua, we analyzed p38 and the ER stress pathway because they are upstream inducers of $\operatorname{ATF} 3(30,31)$. Phosphorylated p38 increased immediately after exercise (3.4 \pm 0.8 -fold; $P<0.05$ ) and then returned to resting levels (Fig. 1E). For ER stress, we measured the protein levels of ATF4 and BiP. No significant changes in BiP were observed, and ATF4 was undetectable (Fig. 1E). Additionally, there were no changes in the mRNA level of the ER stress-responsive genes growth arrest and DNA damageinducible protein-34 (gadd34), CCAAT/enhancer-binding protein homologous protein (chop), and X-box binding protein-1 ( $x b p 1)$ (Fig. 1F).

To test whether the atf3 response occurred in other tissues, we analyzed Epi. The atf3 mRNA level did not change after exercise (Fig. 1G), and the protein was undetectable (Fig. 1H).

\section{Muscle phenotype is not altered in ATF3-KO mice}

To test the influence of ATF3 in skeletal muscle, we analyzed ATF3-KO and Con mice. Body mass was not different between genotypes up to $12 \mathrm{wk}$ of age (Fig. 2A). Similarly, there was no difference between genotypes in 
A

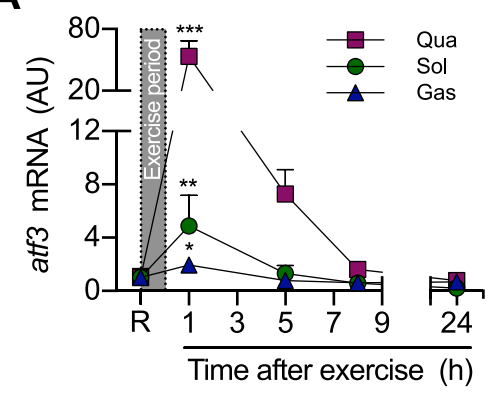

B

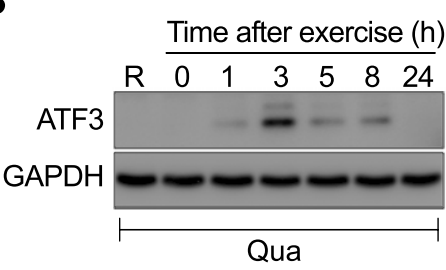

C

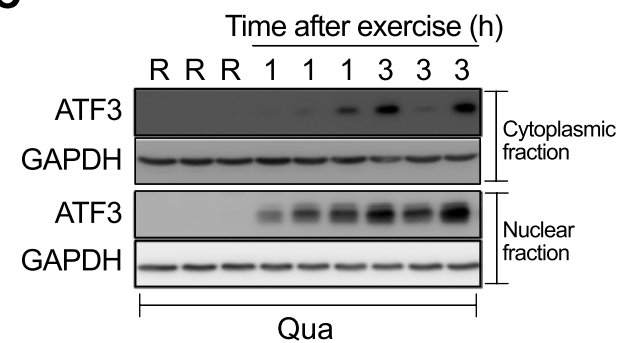

D

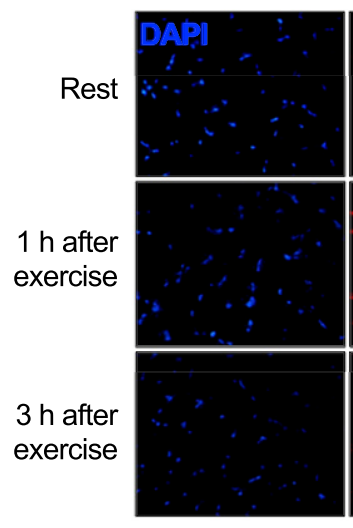

$\mathbf{F}$

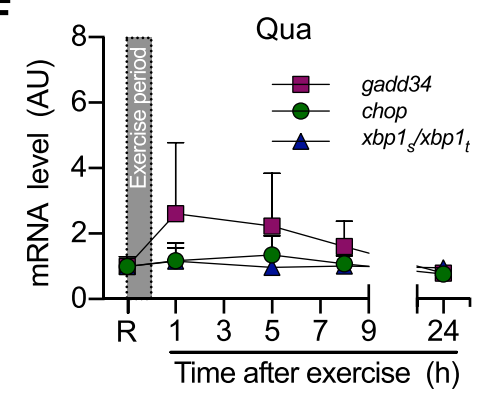

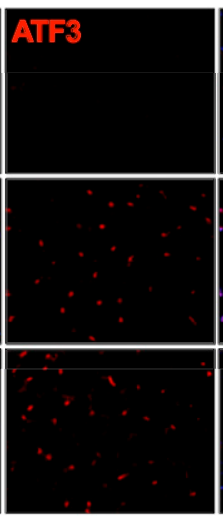

Merge

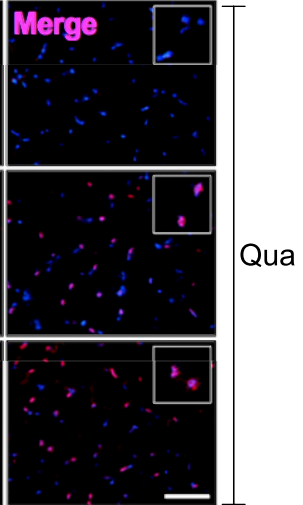

G

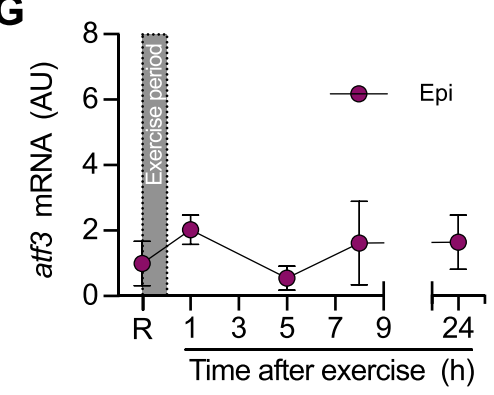

E

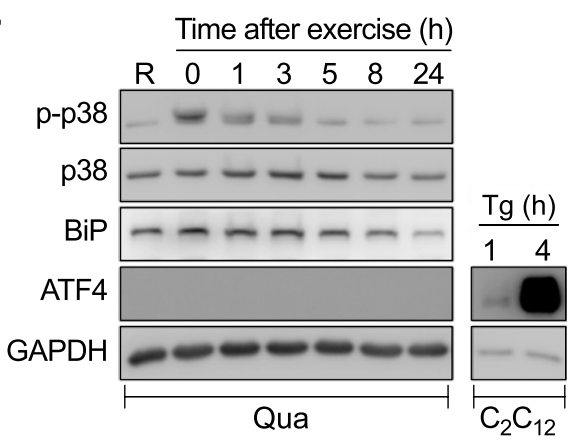

H

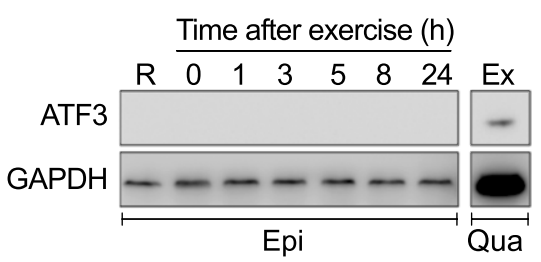

Figure 1. Transient increase in atf3 expression in skeletal muscle after exercise. $A, B)$ Kinetics of atf3 mRNA $(A)$ and protein $(B)$ expression in skeletal muscle after exercise. $C, D$ ) ATF3 protein localization in skeletal muscle after exercise, determined by Western blotting $(C)$ and immunofluorescence $(D)$. Scale bar, $50 \mu \mathrm{m}$. E) Protein levels of phosphorylated p38 (p-p38), BiP, and ATF4 in skeletal muscle after exercise. $\mathrm{C}_{2} \mathrm{C}_{12}$ myotubes stimulated with thapsigargin (Tg) were used as positive Con for ATF4. $F$ ) Kinetics of the mRNA of $g a d d 34, c h o p$, and $x b p 1_{\text {spliced }} / x b p 1_{\text {total }}$ in skeletal muscle after exercise. $\left.G, H\right)$ Kinetics of atf3 mRNA $(G)$ and protein $(H)$ expression in Epi after exercise. Muscle dissected $2 \mathrm{~h}$ after exercise $(\mathrm{Ex})$ was used as positive Con for ATF3 $(H)$. Female mice were used in $C$ and $D$; other data were obtained from male mice. Data represent means \pm SD $(n=3)$. The error bars are not shown if they are smaller than the symbol. AU, arbitrary units. $* P<0.05, * * P<0.01, * * * P<0.001$ vs. rest (R).

the mass of adipose pads (Fig. $2 B$ ) or skeletal muscles (Fig. 2C).

Several parameters were measured to characterize skeletal muscle physiology. No differences were found between Con and ATF3-KO mice for expression of metabolic proteins (i.e., SDH-A, COX IV, and GAPDH) (Fig. $2 D-G$ ), activities of PFK (Fig. $2 H$ ) and CS (Fig. 2I), fiber type (Fig. 2J, $L$ ), and fiber CSA (Fig. 2K, $L$ ).

\section{ATF3 regulates chemokine and cytokine expression in skeletal muscle}

ATF3-KO and Con mice had no difference in performance when subjected to an exhaustive exercise protocol (Fig. $3 A$ ). As expected, atf3 mRNA increased in muscles of Con mice after exercise (Fig. 3B) but was undetectable in ATF3$\mathrm{KO}$ mice. ATF3 protein levels became detectable after exercise in the muscles of Con mice but remained absent in ATF3-KO mice (Fig. 3C).

Microarray analysis of Qua identified 371 genes that were $\geq 1.5$-fold up- or down-regulated in $\mathrm{KO}$ vs. Con mice after exercise (see Supplemental Data for the full list, and Fig. 3D for selected genes). By submitting these 371 genes to the DAVID web tool, we found that the absence of ATF3 significantly influenced chemotaxis, extracellular components, and chemokine/cytokine activities after exercise (Fig. 3E). Similar results were observed at rest and when comparing the response to exercise between genotypes (Supplemental Data).

We selected some chemokines for analysis by quantitative PCR in Qua and Sol. ATF3-KO mice had 

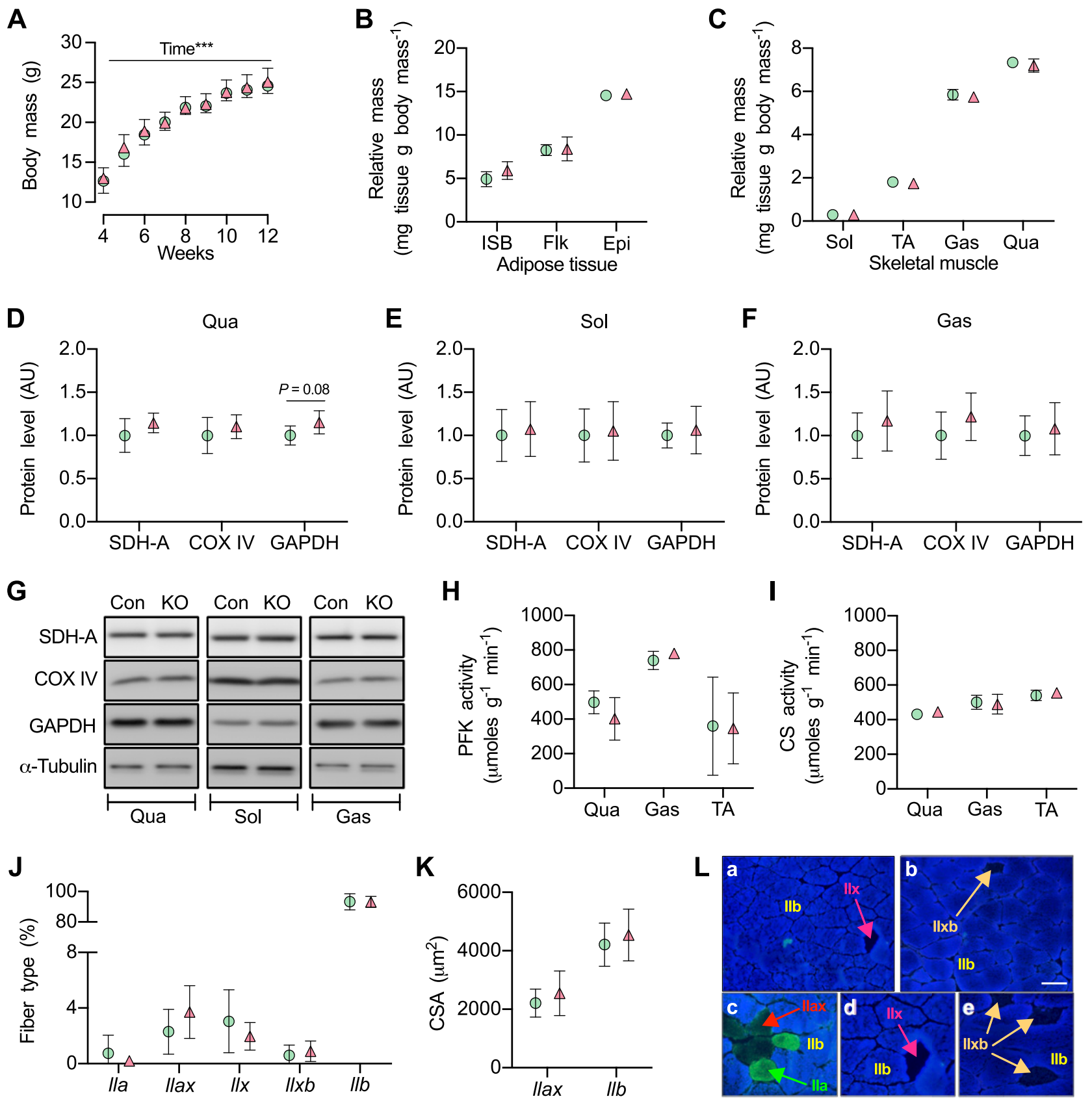

Figure 2. Muscle phenotype is not altered in ATF3-KO mice. Different parameters were compared between resting ATF3-KO and Con mice. $A)$ Body mass $(n=15-20)$. $* * * P<0.001$ for main effect of time. $B, C)$ Masses of adipose tissue pads $(B)$ and skeletal muscles $(C) . D-G)$ Expression of metabolic proteins in Qua $(D, G)$, Sol $(E, G)$, and Gas $(F, G)$ skeletal muscles. $H)$ PFK activity. $I)$ CS activity. $J, K)$ Fiber type percentage $(J)$ and CSA $(K)$ in the lateral portion of Qua. $L)$ Representative images of fiber types in Con $(a)$ and ATF3-KO mice $(b)$; all the fiber types detected are shown as technical Con $(c-e)$. Scale bar, $50 \mu m$. Data represent means \pm SD. The error bars are not shown if they are smaller than the symbol. For $B-K, n=3-5$. Flk, flank subcutaneous; ISB, interscapular brown; TA, tibialis anterior.

higher mRNA levels of $c c l 8$ and $c x c l 13$ in Qua than Con mice (Fig. 3F). Similar results for ccl9 and cxcl13 were found in Sol (Fig. 3G). Interestingly, in Sol, the ccl2 mRNA increased after exercise only in ATF3-KO mice (Fig. 3G). A similar trend was observed for $c x c l 1$ mRNA (Fig. 3G). Because the canonical role of chemokines is leukocyte chemoattraction (32), we quantified the
mRNA of the macrophage-specific marker $c d 68$. No effect was observed in Qua (Fig. 3H), whereas in Sol, cd68 mRNA increased after exercise only in ATF3-KO mice (Fig. 3I).

Il6 and $i l 1 \beta$ were also analyzed because these cytokines are up-regulated in skeletal muscle upon inflammatory insults (22). No effect was observed in Qua (Fig. 3J). In Sol, 


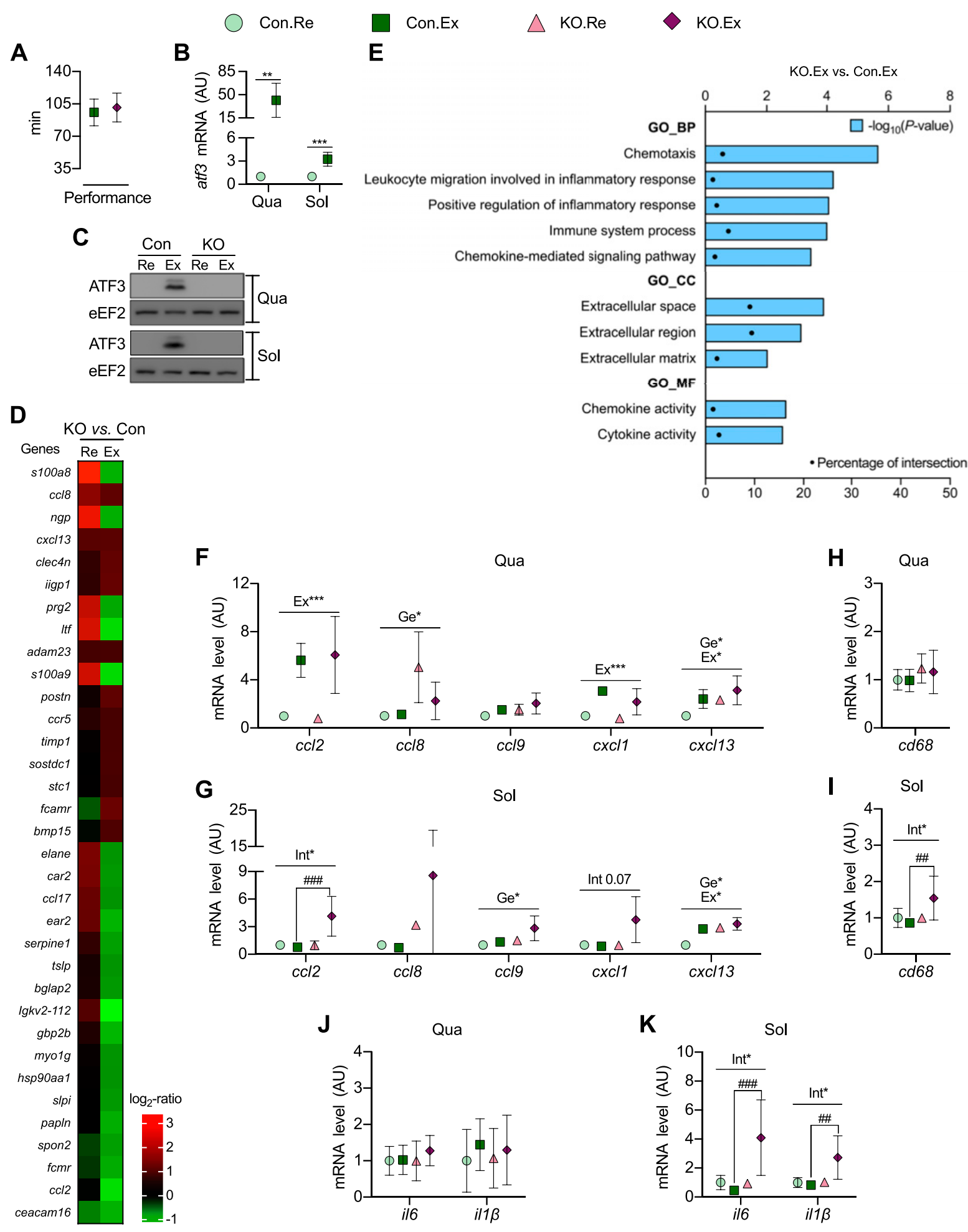

Figure 3. ATF3 regulates chemokine and cytokine expression in skeletal muscle. ATF3-KO and Con mice were exercised (Ex) or remained at rest (Re). A) Time to exhaustion during exercise. $B, C)$ Atf 3 mRNA $(B)$ and protein $(C)$ expression in Qua and Sol of Con mice. $D$ ) Heat map with selected genes $\geq 1$.5-fold up- or down-regulated in $\mathrm{KO}$ vs. Con mice. E) Gene ontology using the genes $\geq 1.5$-fold up- or down-regulated in KO vs. Con after exercise. Only significantly modified terms are presented as $-\log _{10}$ $(P)>1.3$. Percentage of intersection represents the percentage of genes regulated in KO.Ex vs. Con.Ex in relation to the genes in the DAVID database. $F, G)$ mRNA of chemokines in Qua $(F)$ and Sol. $(G) . H, I) C d 68$ mRNA in Qua $(H)$ and Sol. $(I) . J$, K) mRNA of cytokines in Qua $(J)$ and Sol. $(K)$. BP, biological process; CC, cellular component; GO, gene ontology; MF, molecular function. Data represent means $\pm \mathrm{SD}(n=5-6)$. The error bars are not shown if they are smaller than the symbol. $* P<0.05$, $* * P<0.01$, $* * * P<0.001$ for the main effects of genotype (Ge), exercise (Ex), or the interaction genotype/exercise (Int); ${ }^{\# \#} P<0.01$, ${ }^{\# \# \#} P<0.001$ for post hoc test. 
the mRNA level of these cytokines increased after exercise only in ATF3-KO mice (Fig. 3K).

\section{Some molecular adaptations to training are impaired in the Qua of ATF3-KO mice}

During the 8-wk period, sedentary and trained mice increased their body mass independently of genotype (Fig. 4A). As expected, the increase was higher in sedentary mice $(13.5 \pm 4.4 \%)$ than in trained mice $(3.0 \pm 4.5 \%)$. Epi mass decreased after training independently of genotype (Fig. 4B). No effects were observed in the mass of Qua (Fig. 4B) or Sol (Supplemental Fig. 2A). Moreover, the $V_{\max }$ at the end of the training period was not different between genotypes (Supplemental Fig. 2B).

Markers of the mitochondrial content, metabolism of glucose and lipids, antioxidant capacity, and contractile elements were quantified in Qua. CS activity (Fig. 4C) and COX IV protein levels (Fig. 4D, K) increased after training independently of genotype. A similar trend was observed for SDH-A (Fig. 4D, K). The protein levels of GAPDH and GLUT4 were not affected by any condition (Fig. 4E, K). Interestingly, the mRNA level of hexokinase-2 $(h k 2)$ (Fig. 4F), hormone-sensitive lipase (hsl) (Fig. 4G), glutathione peroxidase-1 (gpx1) (Fig. 4I), myosin heavy chain (myhc)-IIa (Fig. 4J), myhc-IIx (Fig. 4J), and myhc-IIb (Fig. 4J) increased in Con mice after training but not in ATF3-KO mice. The mRNA levels of $h k 2$ (Fig. 4F) and myhc-IIa (Fig. 4J) were significantly higher in Con mice than in ATF3-KO mice after training. A trend for the same response was observed for hsl mRNA (Fig. 4G). Catalase (Cat) protein level increased after training in Con mice but not in ATF3-KO mice (Fig. 4H, K). Trends for similar responses were found for the mRNA of cat (Fig. 4I) and myhc-I (Fig. 4J).

Some markers were also analyzed in Sol. COX IV (Supplemental Fig. 2C, J) and Cat protein levels (Supplemental Fig. 2G, J) increased with training independently of genotype. SDH-A tended to respond similarly (Supplemental Fig. $2 C, J)$. No other markers responded to training in Sol (Supplemental Fig. 2D-J).

Finally, the response to training of cytokine genes was quantified. In Qua, il6 mRNA tended to decrease after training in Con mice but to increase in ATF3-KO mice (Supplemental Fig. 3A). In Sol, il1 $\beta$ mRNA decreased after training in Con mice but increased in ATF3-KO mice (Supplemental Fig. 3B).

\section{DISCUSSION}

For the first time, we show here that: 1) postexercise atf3 up-regulation in skeletal muscle is transient in nature, 2) whole-body ATF3 absence does not affect skeletal muscle phenotype at rest, 3) exercise-induced ATF3 attenuates the mRNA expression of chemokines and cytokines in skeletal muscle, and 4) some molecular adaptations to training are impaired in skeletal muscle of ATF3-KO mice. Together, our results support the notion that atf3 is a stress-inducible gene that helps recover skeletal muscle homeostasis after acute exercise. The lack of this regulation impairs the normal adaptation of skeletal muscle to exercise training.

Postexercise atf3 induction in skeletal muscle has been documented in different models (10-14). However, the kinetics of induction have not been determined. We showed that atf3 mRNA and protein peaked 1 and $3 \mathrm{~h}$ after exercise, respectively, returning to basal levels at $24 \mathrm{~h}$. ATF3 localized at the cell nuclei, from where it can regulate gene transcription. Any cell type present in skeletal muscle might be responsible for this atf3 response. Macrophages and myofibers are plausible options because they up-regulate atf3 under other conditions $(7,33-35)$. Eccentric contractions produce muscle damage, leading to activation of resident macrophages along with macrophage infiltration from the bloodstream $(29,36)$. Concentric contractions are not associated with these phenomena. We observed atf3 induction after exercise in the flat treadmill (no slope), in which contractions are mostly concentric. This observation suggests that muscle-damaging contractions (eccentric) are not necessary for atf3 induction. Consequently, macrophage activation and/or infiltration do not seem to be the main factors responsible for the postexercise atf3 response. We thereby believe myofibers are the most probable cell type explaining the postexercise atf3 up-regulation. Further studies are needed to confirm this hypothesis.

Several signaling pathways have been related to the regulation of atf3 (5). We focused on p38 and ER stress because they both respond to exercise in skeletal muscle $(10,37)$. In vitro, p38 is necessary and sufficient for atf 3 induction upon different stimuli (30). We observed that p38 phosphorylation increased immediately after exercise, followed by atf3 induction at $1 \mathrm{~h}$. This kinetics is compatible with an implication of p38 in the atf3 induction in skeletal muscle. However, in vitro studies are required to directly test that association. We also examined ER stress because atf3 is a downstream target of ATF4 (31). No signal of ER stress was detected, suggesting that ER stress is not necessary for ATF3 induction in exercised muscles.

Previous evidence shows ATF3-KO mice have no obvious phenotype under unstressed conditions (20, $38-40$ ). This is not surprising because at $f 3$ is a stimulusresponsive gene. In the same line, we found no alteration in the muscular phenotype of resting ATF3-KO mice. Although exercise is a stressful stimulus, we observed no difference in acute exercise performance between ATF3-KO and Con mice. This might be explained by the unaltered muscle phenotype in ATF3-KO mice together with the fact that ATF3 increases only after exercise.

Because ATF3 is a transcription factor, we expected gene expression of skeletal muscle postexercise to be altered in ATF3-KO mice. We did an unbiased gene analysis by microarray to verify that hypothesis. Our results showed ATF3 regulates various immune response genes in skeletal muscle, agreeing with previous reports in macrophages, pancreatic islets, lung, and cardiac tissue $(6,9,33,40-42)$. Specifically, we found ATF3 

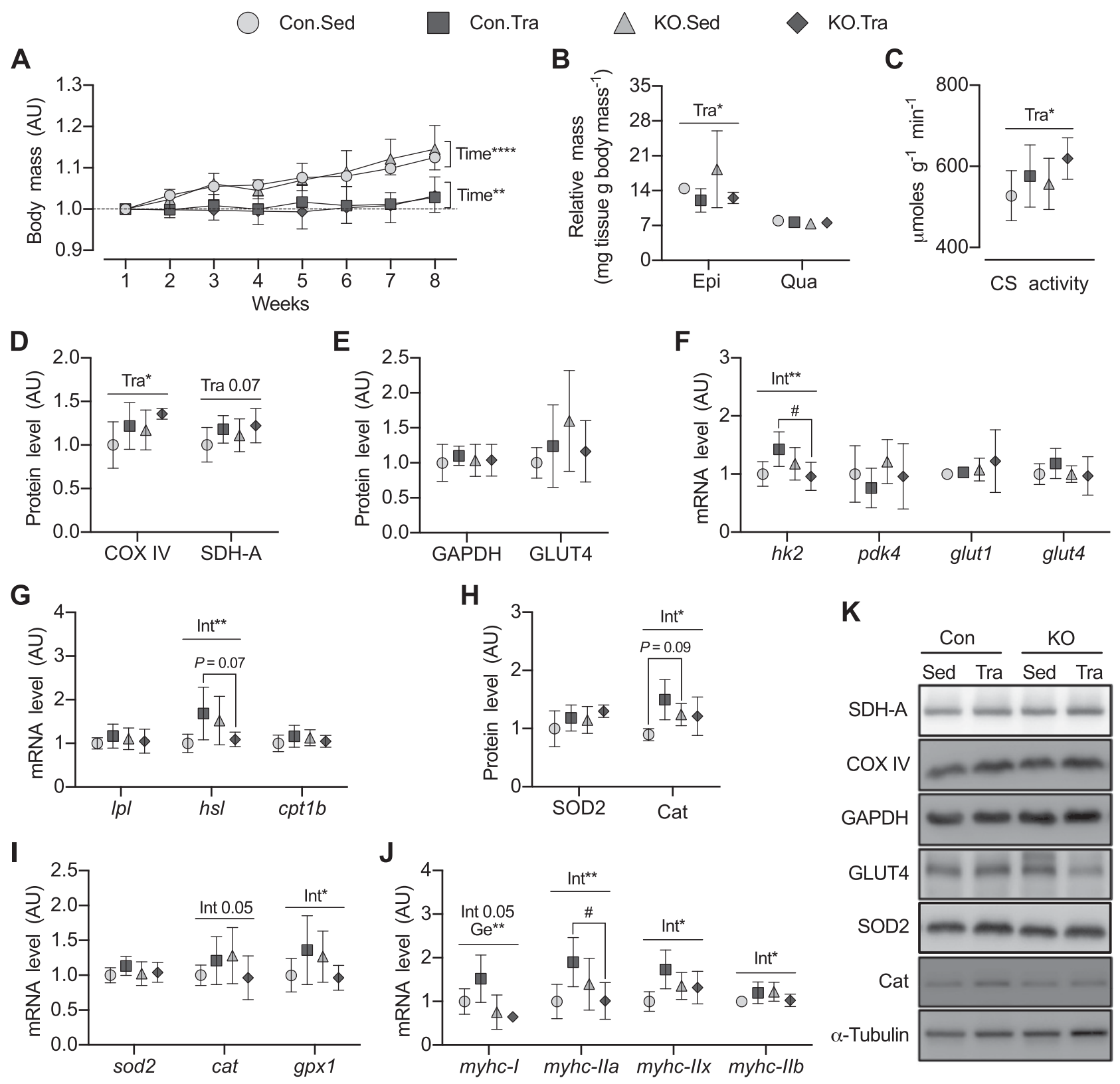

Figure 4. Impaired molecular adaptation to endurance training in Qua of ATF3-KO mice. ATF3-KO and Con mice were trained (Tra) or remained sedentary (Sed). Several markers were then compared. A) Changes in body mass relative to the values of wk $1 . B$ ) Relative tissue masses. $C$ ) CS activity. $D, E)$ Expression of mitochondrial $(D)$ and glycolytic $(E)$ proteins. $F, G)$ mRNA level of genes of the glucose $(F)$ and lipid $(G)$ metabolism. $H, I)$ Protein $(H)$ and mRNA $(I)$ expression of antioxidant enzymes. $J$ ) mRNA level of myosin heavy chain isoforms. $K$ ) Representative Western blots for the analyses in $D, E$, and $H$. Data represent means \pm SD $(n=5-6)$. The error bars are not shown if they are smaller than the symbol. $* P<0.05$, $* * P<0.01, * * * * P<0.0001$ for main effects of time, genotype (Ge), training (Tra), or interaction genotype/training (Int); ${ }^{\#} P<0.05$ for post hoc test.

regulates the expression of chemotaxis-related transcripts, among them chemokines. Chemokine expression was exacerbated in muscles of ATF3-KO mice, as shown before in other tissues of these mice upon exposure to pathological stimuli $(6,9,40,41)$. We observed higher mRNA levels of $c c l 8, c c l 9$, and $c^{2} c l 13$ in muscles of ATF3-KO mice. Also, the mRNA level of $c c l 2$ and $c x c l 1$ $(P=0.07)$ increased only in Sol of ATF3-KO mice after exercise, which was accompanied with signals of macrophage infiltration. Importantly, except for cxcl13, all chemokines analyzed here are inflammatory (32). Also associated with inflammation (22), ATF3-KO mice presented higher mRNA levels of $i l 6$ and $i l 1 \beta$ in Sol after exercise. Our results thus indicate that ATF3 attenuates the mRNA expression of inflammation-related genes in skeletal muscle after exercise.

At a mechanistic level, ATF3 might directly regulate chemokine/cytokine expression. Putative ATF3 binding sites exist in all the chemokine/cytokine genes we studied (unpublished observations). In addition, ATF3 binding to 
the genes $i l 6, i l 1 \beta$, and $c c l 2$ has been demonstrated previously $(7,33,42,43)$. Alternatively, ATF3 might regulate chromatin organization close to the cluster of chemokine genes. Interaction of ATF3 with histone deacetylases has been shown $(33,44)$. Future studies should identify the mechanisms whereby ATF3 regulates chemokines and cytokines in skeletal muscle.

Inflammation is known to contribute to the pathogenesis of many diseases $(3,45)$. Thus, ATF3 upregulation could be beneficial in case of muscle inflammation. For instance, mice fed a high-fat diet develop obesity and insulin resistance and present higher mRNA levels of $t n f \alpha$, il6, and $c c l 2$ in Gas (46). Exercise training did not prevent high-fat dietinduced obesity, but it did prevent insulin resistance and the altered muscle gene expression (46). Perhaps, exercise-induced ATF3 in muscle played a role in those protective effects. Other alterations in which ATF3 might be protective are muscle myopathies. Chemokine C-C motif ligand-2 is proposed to participate in the pathogenesis of Duchenne muscular dystrophy (47). Regulating ccl2 expression through ATF3 might influence the evolution of the pathology. Finally, ATF3 could also be important during recovery from muscle injury because chemokine signaling is crucial for muscle regeneration (48-50). Our results thus open a window into the study of ATF3 in different contexts of muscle physiology.

Endurance training induces many adaptations that reduce the risk of developing metabolic chronic diseases (51). By increasing energy expenditure, training helps to regulate total body and fat masses $(2,51,52)$. In agreement, our trained mice increased less in their body mass during the 8-wk experimental period and had less Epi than sedentary mice. Endurance training also produces mitochondrial biogenesis in skeletal muscle (1). Accordingly, we found higher CS activity and COX IV expression in muscles of trained mice compared with sedentary mice. All these adaptations were independent of the genotype, indicating ATF3 does not play a role.

Muscle remodeling induced by training also includes adaptations in the metabolism of glucose and lipids, antioxidant capacity, and contractile elements $(1,51,53)$. We observed that training increased the basal mRNA level of $h k 2, h s l, g p x 1$, myhc-IIa, myhc-IIx, and myhc-IIb in Qua of Con mice. The same occurred with Cat protein level. Notably, these molecular adaptations were blunted in ATF3-KO mice, showing ATF3 is necessary for their production. We speculate that the deregulated postexercise expression of inflammation-related genes in ATF3-KO mice interferes with part of their adaptive capacity. Of note, trained ATF3-KO mice performed normally in an incremental test until exhaustion, despite their blunted molecular adaptation to training. Longer and/or more intensive training might thus be required to impair performance.

Some training adaptations occurred only in Qua, not in Sol. The different fiber type composition between these muscles might explain these results. Mouse Sol is mainly composed of oxidative fibers, whereas Qua is a mixed muscle (24). Oxidative fibers have a better capacity for lipid degradation, higher rates of exercise-induced glucose uptake, and more antioxidant defenses (53-55). Consequently, Sol is better prepared for endurance exercise than Qua. A more pronounced adaptation to endurance training is thereby expected in Qua.

Our data demonstrate that ATF3 keeps in check various inflammatory genes after exercise. This regulation has been extensively shown in different cells and tissues in pathophysiological contexts, such as sepsis, cancer, allergy, obesity, and others $(8,9,33,56)$. We studied ATF3 function by using a physiological stress (i.e., exercise). To the best of our knowledge, this is the first report indicating that the atf3 gene is functionally important in a physiological context.

In summary, we demonstrated that exercise-induced ATF3 attenuates the mRNA expression of inflammatory chemokines and cytokines in skeletal muscle. This response to acute exercise influences some molecular adaptations to endurance training. Because inflammation participates in the pathogenesis of many diseases $(3,45)$, the identification of anti-inflammatory molecules is essential. Our results show that ATF3 is a negative regulator of some inflammatory genes in skeletal muscle.

\section{ACKNOWLEDGMENTS}

This work was supported by the Belgian Fonds National de la Recherche Scientifique (FSR-FNRS, No. 23628981) and by funds from the Comisión Nacional de Investigación Científica y Tecnológica de Chile (CONICYT) (to R.F.-V.). The authors thank Damien Naslain (Université Catholique de Louvain) for technical assistance and Tijs Vandoorne (Katholieke Universiteit Leuven, Leuven, Belgium) for collaboration with the fiber typing method.

\section{AUTHOR CONTRIBUTIONS}

R. Fernández-Verdejo, T. Hai, L. Deldicque, and M. Francaux conceived the study; R. Fernández-Verdejo, A. M. Vanwynsberghe, A. Essaghir, and L. Deldicque acquired the data; R. Fernández-Verdejo wrote the manuscript; and all authors participated in designing the study, in analyzing and interpreting the data, and in revising the manuscript.

\section{REFERENCES}

1. Hawley, J. A., Hargreaves, M., Joyner, M. J., and Zierath, J. R. (2014) Integrative biology of exercise. Cell 159, 738-749

2. Garber, C. E., Blissmer, B., Deschenes, M. R., Franklin, B. A., Lamonte, M. J., Lee, I. M., Nieman, D. C., and Swain, D. P.; American College of Sports Medicine. (2011) American College of Sports Medicine position stand. Quantity and quality of exercise for developing and maintaining cardiorespiratory, musculoskeletal, and neuromotor fitness in apparently healthy adults: guidance for prescribing exercise. Med. Sci. Sports Exerc. 43, 1334-1359

3. Lancaster, G. I., and Febbraio, M. A. (2014) The immunomodulating role of exercise in metabolic disease. Trends Immunol. 35, 262-269

4. Hai, T., and Hartman, M. G. (2001) The molecular biology and nomenclature of the activating transcription factor/cAMP responsive 
element binding family of transcription factors: activating transcription factor proteins and homeostasis. Gene 273, 1-11

5. Hai, T., Wolford, C. C., and Chang, Y. S. (2010) ATF3, a hub of the cellular adaptive-response network, in the pathogenesis of diseases: is modulation of inflammation a unifying component? Gene Expr. 15, $1-11$

6. Boespflug, N. D., Kumar, S., McAlees, J. W., Phelan, J. D., Grimes, H. L., Hoebe, K., Hai, T., Filippi, M. D., and Karp, C. L. (2014) ATF3 is a novel regulator of mouse neutrophil migration. Blood 123, 2084-2093

7. Nguyen, C. T., Kim, E. H., Luong, T. T., Pyo, S., and Rhee, D. K. (2014) ATF3 confers resistance to pneumococcal infection through positive regulation of cytokine production. J. Infect. Dis. 210, 1745-1754

8. Wolford, C. C., McConoughey, S. J., Jalgaonkar, S. P., Leon, M., Merchant, A. S., Dominick, J. L., Yin, X., Chang, Y., Zmuda, E. J., O'Toole, S. A., Millar, E. K., Roller, S. L., Shapiro, C. L., Ostrowski, M. C., Sutherland, R. L., and Hai, T. (2013) Transcription factor ATF3 links host adaptive response to breast cancer metastasis. J. Clin. Invest. 123, 2893-2906

9. Gilchrist, M., Henderson, W. R., Jr., Clark, A. E., Simmons, R. M., Ye, X., Smith, K. D., and Aderem, A. (2008) Activating transcription factor 3 is a negative regulator of allergic pulmonary inflammation. J. Exp. Med. 205, 2349-2357

10. Wu, J., Ruas, J. L., Estall, J. L., Rasbach, K. A., Choi, J. H., Ye, L., Boström, P., Tyra, H. M., Crawford, R. W., Campbell, K. P., Rutkowski, D. T., Kaufman, R. J., and Spiegelman, B. M. (2011) The unfolded protein response mediates adaptation to exercise in skeletal muscle through a PGC-1 $\alpha /$ ATF6 $\alpha$ complex. Cell Metab. 13, 160-169

11. McKenzie, M. J., Goldfarb, A. H., and Kump, D. S. (2011) Gene response of the gastrocnemius and soleus muscles to an acute aerobic run in rats. J. Sports Sci. Med. 10, 385-392

12. McKenzie, M. J., and Goldfarb, A. H. (2007) Aerobic exercise bout effects on gene transcription in the rat soleus. Med. Sci. SportsExerc. 39, 1515-1521

13. MacNeil, L. G., Melov, S., Hubbard, A. E., Baker, S. K., and Tarnopolsky, M. A. (2010) Eccentric exercise activates novel transcriptional regulation of hypertrophic signaling pathways not affected by hormone changes. PLoS One 5, e10695

14. McLean, C. S., Mielke, C., Cordova, J. M., Langlais, P. R., Bowen, B., Miranda, D., Coletta, D. K., and Mandarino, L. J. (2015) Gene and microRNA expression responses to exercise: relationship with insulin sensitivity. PLoS One 10, e0127089

15. Bey, L., Akunuri, N., Zhao, P., Hoffman, E. P., Hamilton, D. G., and Hamilton, M. T. (2003) Patterns of global gene expression in rat skeletal muscle during unloading and low-intensity ambulatory activity. Physiol. Genomics 13, 157-167

16. LaFramboise, W. A., Jayaraman, R. C., Bombach, K. L., Ankrapp, D. P., Krill-Burger, J. M., Sciulli, C. M., Petrosko, P., and Wiseman, R. W. (2009) Acute molecular response of mouse hindlimb muscles to chronic stimulation. Am. J. Physiol. Cell Physiol. 297, C556-C570

17. Koya, T., Nishizawa, S., Ohno,Y., Goto, A., Ikuta, A., Suzuki, M., Ohira, T., Egawa, T., Nakai, A., Sugiura, T., Ohira, Y., Yoshioka, T., Beppu, M., and Goto, K. (2013) Heat shock transcription factor 1-deficiency attenuates overloading-associated hypertrophy of mouse soleus muscle. PLoS One 8, e77788

18. Barash, I. A., Mathew, L., Ryan, A. F., Chen, J., and Lieber, R. L. (2004) Rapid muscle-specific gene expression changes after a single bout of eccentric contractions in the mouse. Am. J. Physiol. Cell Physiol. 286, C355-C364

19. Warren, G. L., Summan, M., Gao, X., Chapman, R., Hulderman, T., and Simeonova, P. P. (2007) Mechanisms of skeletal muscle injury and repair revealed by gene expression studies in mouse models. J. Physiol. 582, 825-841

20. Hartman, M. G., Lu, D., Kim, M. L., Kociba, G.J., Shukri, T., Buteau, J., Wang, X., Frankel, W. L., Guttridge, D., Prentki, M., Grey, S. T., Ron, D., and Hai, T. (2004) Role for activating transcription factor 3 in stress-induced beta-cell apoptosis. Mol. Cell. Biol. 24, 5721-5732

21. Vandesompele, J., De Preter, K., Pattyn, F., Poppe, B., Van Roy, N., De Paepe, A., and Speleman, F. (2002) Accurate normalization of real-time quantitative RT-PCR data by geometric averaging of multiple internal control genes. Genome Biol. 3, RESEARCH0034

22. Rodriguez, J., Fernández-Verdejo, R., Pierre, N., Priem, F., and Francaux, M. (2016) Endurance training attenuates catabolic signals induced by TNF- $\alpha$ in muscle of mice. Med. Sci. Sports Exerc. 48, 227-234

23. Deldicque, L., Atherton, P., Patel, R., Theisen, D., Nielens, H., Rennie, M. J., and Francaux, M. (2008) Effects of resistance exercise with and without creatine supplementation on gene expression and cell signaling in human skeletal muscle. J. Appl. Physiol. 104, 371-378

24. Bloemberg, D., and Quadrilatero, J. (2012) Rapid determination of myosin heavy chain expression in rat, mouse, and human skeletal muscle using multicolor immunofluorescence analysis. PLoS One 7, e35273

25. McCall, G. E., Byrnes, W. C., Dickinson, A. L., and Fleck, S. J. (1998) Sample size required for the accurate determination of fiber area and capillarity of human skeletal muscle. Can. J. Appl. Physiol. 23, 594-599

26. Huang, da W., Sherman, B. T., and Lempicki, R. A. (2009) Systematic and integrative analysis of large gene lists using DAVID bioinformatics resources. Nat. Protoc. 4, 44-57

27. Hoaglin, D. C., and Iglewicz, B. (1987) Fine tuning some resistant rules for outlier labeling. J. Am. Stat. Assoc. 82, 1147-1149

28. Noble, W. S. (2009) How does multiple testing correction work? Nat. Biotechnol. 27, 1135-1137

29. Paulsen, G., Mikkelsen, U. R., Raastad, T., and Peake, J. M. (2012) Leucocytes, cytokines and satellite cells: what role do they play in muscle damage and regeneration following eccentric exercise? Exerc. Immunol. Rev. 18, 42-97

30. Lu, D., Chen, J., and Hai, T. (2007) The regulation of ATF3 gene expression by mitogen-activated protein kinases. Biochem. J. 401, 559-567

31. Jiang, H. Y., Wek, S. A., McGrath, B. C., Lu, D., Hai, T., Harding, H. P., Wang, X., Ron, D., Cavener, D. R., and Wek, R. C. (2004) Activating transcription factor 3 is integral to the eukaryotic initiation factor 2 kinase stress response. Mol. Cell. Biol. 24, 1365-1377

32. Le, Y., Zhou, Y., Iribarren, P., and Wang, J. (2004) Chemokines and chemokine receptors: their manifold roles in homeostasis and disease. Cell. Mol. Immunol. 1, 95-104

33. Gilchrist, M., Thorsson, V., Li, B., Rust, A. G., Korb, M., Roach, J. C., Kennedy, K., Hai, T., Bolouri, H., and Aderem, A. (2006) Systems biology approaches identify ATF3 as a negative regulator of Toll-like receptor 4. Nature 441, 173-178

34. Alter, J., and Bengal, E. (2011) Stress-induced C/EBP homology protein $(\mathrm{CHOP})$ represses $\mathrm{MyoD}$ transcription to delay myoblast differentiation. PLoS One 6, e29498

35. Lim, J. H., Lee, J. I., Suh, Y. H., Kim, W., Song, J. H., and Jung, M. H. (2006) Mitochondrial dysfunction induces aberrant insulin signalling and glucose utilisation in murine C2C12 myotube cells. Diabetologia 49, 1924-1936

36. Pillon, N. J., Bilan, P. J., Fink, L. N., and Klip, A. (2013) Cross-talk between skeletal muscle and immune cells: muscle-derived mediators and metabolic implications. Am. J. Physiol. Endocrinol. Metab. 304, E453-E465

37. Zbinden-Foncea, H., Raymackers, J. M., Deldicque, L., Renard, P., and Francaux, M. (2012) TLR2 and TLR4 activate p38 MAPK and JNK during endurance exercise in skeletal muscle. Med. Sci. Sports Exerc. 44, 1463-1472

38. Zmuda, E. J., Qi, L., Zhu, M. X., Mirmira, R. G., Montminy, M. R., and Hai, T. (2010) The roles of ATF3, an adaptive-response gene, in highfat-diet-induced diabetes and pancreatic beta-cell dysfunction. Mol. Endocrinol. 24, 1423-1433

39. Zhou, H., Shen, D. F., Bian, Z. Y., Zong, J., Deng, W., Zhang, Y., Guo, Y. Y., Li, H., and Tang, Q. Z. (2011) Activating transcription factor 3 deficiency promotes cardiac hypertrophy, dysfunction, and fibrosis induced by pressure overload. PLoS One 6, e26744

40. Lai, P. F., Cheng, C. F., Lin, H., Tseng, T. L., Chen, H. H., and Chen, S. H. (2013) ATF3 protects against LPS-induced inflammation in mice via inhibiting HMGB1 expression. Evid. Based Complement Alternat. Med. 2013, 716481

41. Zhou, H., Guo, H., Zong, J., Dai, J., Yuan, Y., Bian, Z. Y., and Tang, Q. Z. (2014) ATF3 regulates multiple targets and may play a dual role in cardiac hypertrophy and injury. Int. J. Cardiol. 174, 838-839

42. Zmuda, E. J., Viapiano, M., Grey, S. T., Hadley, G., Garcia-Ocaña, A., and Hai, T. (2010) Deficiency of Atf3, an adaptive-response gene, protects islets and ameliorates inflammation in a syngeneic mouse transplantation model. Diabetologia 53, 1438-1450

43. Takii, R., Inouye, S., Fujimoto, M., Nakamura, T., Shinkawa, T., Prakasam, R., Tan, K., Hayashida, N., Ichikawa, H., Hai, T., and Nakai, A. (2010) Heat shock transcription factor 1 inhibits expression of IL-6 through activating transcription factor 3 . J. Immunol. 184, 1041-1048

44. Darlyuk-Saadon, I., Weidenfeld-Baranboim, K., Yokoyama, K. K., Hai, T., and Aronheim, A. (2012) The bZIP repressor proteins, c-Jun dimerization protein 2 and activating transcription factor 3 , recruit 
multiple HDAC members to the ATF3 promoter. Biochim. Biophys. Acta 1819, 1142-1153

45. Turner, M. D., Nedjai, B., Hurst, T., and Pennington, D. J. (2014) Cytokines and chemokines: at the crossroads of cell signalling and inflammatory disease. Biochim. Biophys. Acta 1843, 2563-2582

46. Samaan, M. C., Marcinko, K., Sikkema, S., Fullerton, M. D., Ziafazeli, T., Khan, M. I., and Steinberg, G. R. (2014) Endurance interval training in obese mice reduces muscle inflammation and macrophage content independently of weight loss. Physiol. Rep. 19, e12012.

47. Porter, J. D., Guo, W., Merriam, A. P., Khanna, S., Cheng, G., Zhou, X., Andrade, F. H., Richmonds, C., and Kaminski, H. J. (2003) Persistent over-expression of specific CC class chemokines correlates with macrophage and T-cell recruitment in mdx skeletal muscle. Neuromuscul. Disord. 13, 223-235

48. Griffin, C. A., Apponi, L. H., Long, K. K., and Pavlath, G. K. (2010) Chemokine expression and control of muscle cell migration during myogenesis. J. Cell Sci. 123, 3052-3060

49. Warren, G. L., O'Farrell, L., Summan, M., Hulderman, T., Mishra, D., Luster, M. I., Kuziel, W. A., and Simeonova, P. P. (2004) Role of CC chemokines in skeletal muscle functional restoration after injury. Am. J. Physiol. Cell Physiol. 286, C1031-C1036

50. Warren, G. L., Hulderman, T., Mishra, D., Gao, X., Millecchia, L., O'Farrell, L., Kuziel, W. A., and Simeonova, P. P. (2005) Chemokine receptor CCR2 involvement in skeletal muscle regeneration. FASEBJ. 19, 413-415
51. Egan, B., and Zierath, J. R. (2013) Exercise metabolism and the molecular regulation of skeletal muscle adaptation. Cell Metab. 17, 162-184

52. Gleeson, M., Bishop, N. C., Stensel, D. J., Lindley, M. R., Mastana, S. S., and Nimmo, M. A. (2011) The anti-inflammatory effects of exercise: mechanisms and implications for the prevention and treatment of disease. Nat. Rev. Immunol. 11, 607-615

53. Powers, S. K., and Jackson, M. J. (2008) Exercise-induced oxidative stress: cellular mechanisms and impact on muscle force production. Physiol. Rev. 88, 1243-1276

54. Fueger, P. T., Heikkinen, S., Bracy, D. P., Malabanan, C. M., Pencek, R. R., Laakso, M., and Wasserman, D. H. (2003) Hexokinase II partial knockout impairs exercise-stimulated glucose uptake in oxidative muscles of mice. Am. J. Physiol. Endocrinol. Metab. 285, E958-E963

55. Kiens, B. (2006) Skeletal muscle lipid metabolism in exercise and insulin resistance. Physiol. Rev. 86, 205-243

56. Suganami, T., Yuan, X., Shimoda, Y., Uchio-Yamada, K., Nakagawa, N., Shirakawa, I., Usami, T., Tsukahara, T., Nakayama, K., Miyamoto, Y., Yasuda, K., Matsuda, J., Kamei, Y., Kitajima, S., and Ogawa, Y. (2009) Activating transcription factor 3 constitutes a negative feedback mechanism that attenuates saturated fatty acid/toll-like receptor 4 signaling and macrophage activation in obese adipose tissue. Circ. Res. 105, 25-32

Received for publication September 9, 2016. Accepted for publication October 31, 2016. 